\title{
Impelementasi Sistem Informasi Manajemen Penggajian Pegawai Pada Kantor Camat Monta Kabupaten Bima Berbasis Web
}

\author{
Haris Tehuayo ${ }^{1}$, Sajiha ${ }^{2}$ \\ ${ }^{1}$ Jurusan Teknik Informatika, Fakultas Teknik, \\ Universitas Islam Makassar, Email: harisristo02@gmail.com \\ ${ }^{2}$ Jurusan Teknik Informatika, Fakultas Teknik, \\ Universitas Islam Makassar, Email: sajiah.dty@uim-makassar.ac.id
}

\begin{abstract}
Abstrak
Pada sistem informasi penggajian pegawai pada Kantor Camat Monta adalah sistem penggajian pegawai yang masih dilakukan secara manual sehingga aktifitas pekerjaan menjadi terhambat dan tidak efisien dan hal ini mengakibatkan bendahara tidak efisien dan efektif dalam melakukan perhitungan penggajian pegawai. Tujuan dari pembuatan sistem ini adalah merancang, dan menguji, sistem penggajian pegawai pada Kantor Camat Monta. Metode pengujian yang digunakan yaitu metode black box testing. Black box testing dilakukan dengan mengamati hasil eksekusi melalui data uji dan memeriksa fungsional dari perangkat lunak. Pengujian black box mengevaluasi hanya dari tampilan luarnya atau interface dan fungsionalitasnya tanpa mengetahui input dan output. Sistem ini dibuat berbasis web menggunakan bahasa pemrograman PHP dan database MySQL. Hasil penelitian menunjukkan bahwa bahwa rancangan dan pengujian sistem informasi penggajian pegawai terdapat sistem informasi di antaranya menu login, halam utama, data pegawai serta data gaji pegawai. Kesimpulan yaitu rancangan dan pengujian dari sistem informasi penggajian pegawai menunjukkan sistem ini dapat dapat membantu dalam memudahkan pencarian informasi penggajian pega wai dengan pencarian informasi yang lebih cepat serta mengatasi kendala tentang ketidak-akuratan laporan-laporan yang berhubungan dengan masalah penggajian pegawai dapat diatasi secara online
\end{abstract}

Kata Kunci: MySQL, PHP, employee payroll

\begin{abstract}
In the employee payroll information system at the Monta Sub-district Office, the employee's payroll system is still done manually so that work activities become obstructed and inefficient and this results in the treasurer being inefficient and effective in calculating employee payroll. The purpose of making this system is to design, test, test, employee payroll systems at the Monta Sub-district Office. The testing method used is the black box testing method. Black box testing is done by storing the results of execution through test data and functional tests of the software. Black box testing arrives only from its external appearance or interface and functionality regardless of input and output. This system is made web-based using the PHP programming language and MySQL database. The results showed that the design and testing of employee payroll information systems contained an information system which included the login menu, main page, employee data and employee salary data. The conclusion is that the design and testing of employee payroll information systems shows that this system can help in making it easier to find employee payroll information by finding information more quickly and overcoming problems regarding inaccurate reports related to employee payroll problems that can be resolved. online.
\end{abstract}

Keywords: MySQL, PHP, Penggajian Pegawai 


\section{Pendahuluan}

Perkembangan teknologi informasi dan komunikasi yang begitu cepat dan pesat menjadikan segala lini kehidupan manusia hampir tidak bisa berlepas diri dari teknologi dan pemanfaatannya, pemanfaatan teknologi inipun kian waktu menjadi tren disemua kalangan mulai dari perseorangan maupun kelompok serta instansi maupun perusahaan. Informasi merupakan kebutuhan yang mutlak bagi perusahaan untuk menjalankan segala aktivitasnya. Salah satu bentuk penerapan untuk menghasilkan informasi yang lebih cepat dan tepat adalah dengan memanfaatkan teknologi informasi. Sistem informasi diharapkan dapat meberikan manfaat dalam meningkatkan keefektifan dan keefisienan dalam perusahaan terutama dalam hal penggajian pegawai atau karyawan perusahaan sehingga sistem penggajian bisa berjalan lebih efektif dan efisien.

Pada penelitian yang dilakukan oleh (Aminudin et al., 2013) [1]. Dengan sistem informasi penggajian pegawai pada kantor kecematan nawangan kabupaten pacitan, akan memepermudah sistem penggajian yang ada disana dan mengurangi kesalahan dalam perhitungan gaji pegawai. Hasil dari penelitian ini adalah untuk memberikan kemudahan dalam mengelola gaji pegawai dengan memiliki media penyimpanan yang lebih efektif. Penelitian lain yang berjudul Sistem Informasi Penggajian Karyawan Pada PT. White Horse Ceramic Indonesia (Haryadi \& Arifin, 2016) [2].Dalam era globalisasi sekarang ini, teknologi informasi melaju dengan cepatnya. Adapun komputer yang merupakan peralatan yang diciptakan untuk mempermudah pekerjaan manusia, mencapai kemajuan baik disalam pembuatan hardware maupun software. PT. White Horse Ceramic Indonesia membutuhkan sekali adanya suatu sistem yang menunjang proses penggajian yang baik bagi para karyawannya, dan masih dilakukan secara manual, mulai dari pencatatan data pegawai dan penyimpanan data-data lainnya yang berhubungan dengan proses transaksi penggajian hingga pembuatan slip gaji, sehingga memungkinkan terjadinya kesalahan dalam pencatatan, yang berpengaruh dalam pembuatan laporan.

Penelitian menurut (Sari \& Permadi, 2018)[6]. Pihak PT. Tirta Sukses Perkasa menginginkan adanya aplikasi penggajian karyawan di perusahaan tersebut. Proses pendataan dilakukan langsung di aplikasi, kemudian aplikasi akan menghitung secara otomatis jumlah gaji karyawan perusahaan. Cara ini diharapkan dapat mengurangi intensitas pekerjaan petugas pencatat (admin keuangan) dalam melakukan rekap gaji dan laporan keuangan, karena tidak diperlukan lagi proses perhitungan secara manual. Sehingga penyusunan laporan tidak dilakukan berulang kali yang pada akhirnya diharapkan pemberian gaji karyawan dilakukan tepat waktu. Aplikasi ini berbasis web agar dapat dimonitoring secara mudah dan cepat. Penelitian lain juga yang berjudul Perancangan Sistem Informasi Penggajian Terintegrasi Berbasis Web (Studi Kasus di Rumah Sakit St. Elisabeth (Suharyanto et al., 2017) [8]. Perhitungan gaji karyawan berbasis database (DBMS) sehingga perincian gaji yang diterima karyawan dapat diketahui dengan jelas dan lebih akurat, serta dapat diakses sewaktu-watu dengan fasilitas search: berdasarkan NRP (Nomor Register Pegawai), nama awal ataupun nama akhir, status karyawan (kontrak atau permanen), jenis kelamin, tanggal masuk, umur, dll. Pada penelitian (Palevi \& Krisnawati, 2014) [3]. diambil pembahasan tentang uji coba program Pada penelitian ini mengunakan black box testing. Pada penelitian ini di ambil pembahasan mengenai informasi (Purnamasari, 2012) [5]. menjelaskan tetang Informasi merupakan salah satu kebutuhan di dalam setiap instansi. Informasi dianggap sangat penting karena dapat menambah pengetahuan, mengurangi ketidakpastian serta dapat membantu para pemimpin dalam mengambil suatu kesimpulan dan keputusan yang efektif dan efisien. Salah satu informasi yang penting dari suatu instansi pemerintah adalah tentang kepegawaian yang terkait dengan apa saja yang termasuk dalam melengkapi data pegawai tersebut. Mulai dari pangkat dan golongan, status, penggajian dan lainlain. Penelitian menurut (Syifani \& Dores, 2018)[9]. Pada penelitian ini juga membahan tentang model waterfall, Metode waterfall adalah metode air terjun atau yang sering disebut metode waterfall sering dinamakan siklus hidup klasik (classic life cycle), dimana hal ini menggambarkan pendekatan yang sistematis dan juga berurutan pada pengembangan perangkat lunak, dimulai dengan spesifikasi kebutuhan pengguna lalu berlanjut melalui tahapan-tahapan perencanaan (planning), permodelan (modeling), konstruksi (construction), serta penyerahan sistem ke para pelanggan/pengguna (deployment), yang diakhiri dengan dukungan pada perangkat lunak lengkap yang dihasilkan.

Pada penelitian di ambil pembahsan basis data (Veza \& Ropianto, 2017) [10]. Basis data terdiri atas dua kata, yaitu basis dan data. Basis kurang lebih dapat diartikan sebagai markas atau gudang, tempat bersarang/berkumpul. Sedangkan Data adalah representasi fakta dunia nyata yang mewakili suatu objek seperti manusia (pegawai, siswa, pembeli, pelanggan), barang, hewan, peristiwa, konsep, keadaan, dan sebagainya. Yang diwujudkan dalam bentuk angka, huruf, simbol, teks, gambar, bunyi atau 
kombinasinya. Pembahasan website menurut (Sidik, 2014) Website merupakan kumpulan data dan informasi dengan berdasarkan topik tertentu yang disediakan secara individu, kelompok atau organisasi, yang dapat diakses oleh publik secara bebas dan praktis. (Prasodjo, 2014) Dengan adanya Undang Undang tersebut membawa perubahan dalam manajemen kepegawaian serta pengembangan kapasitas pegawai di Indonesia yang berdampak pada kinerja pegawai ASN yang diukur setiap tahun secara individual dan sistem penggajian yang berdasar pada beban kerja yang diberikan. Dengan adanya Undang - Undang tersebut membawa perubahan dalam manajemen kepegawaian serta pengembangan kapasitas pegawai di Indonesia yang berdampak pada kinerja pegawai ASN yang diukur setiap tahun secara individual dan sistem penggajian yang berdasar pada beban kerja yang diberikan Prasejo 2017.

Berdasarkan beberapa pendapat, maka penulis mempunyai tujuan dari pembuatan sistem ini adalah merancang, dan menguji, sistem penggajian pegawai yang dapat membantu dalam memudahkan pencarian informasi penggajian pegawai dengan pencarian informasi yang lebih cepat serta mengatasi kendala tentang ketidak-akuratan laporan-laporan yang berhubungan dengan masalah penggajian pegawai dapat diatasi secara online.

\section{Metode Penelitian}

\subsection{Alat}

Pada penelitian ini dibutuhkan alat dan bahan yang digunakan untuk membantu proses pengerjaan penelitian ini, adapun alat yang digunakan adalah terbagi atas dua kategori yaitu perangkat keras dan perangkat lunak. Perangkat keras sendiri diantaranya pertama laptop Asus dengan spesifikasi prosessor intel Prosesor Intel® dual-corel N3060 CPU (2.48 GHz), Memory 4000 MB RAM, dan windows 10 ultimate 64-bit. Laptop ini digukan untuk menjalankan perangkat lunak yang ingin operasikan. Kedua Ponsel Vivo Y91 2019, dengan spesifikasi android OS V 8.1.0, Octa-core $2.0 \mathrm{GHz}$, resolusi 1600 x 720 piksel, 6.5 inchi, dan kapasitas Ram 2 GB. Untuk perangkat lunak yaitu sistem operasi windows 10 (64 bit), bahasa pemrograman PHP, Xampp, sublime text, Micrososft Office 2010.

\subsection{Bahan}

Adapun bahan yang digunakan untuk penelitian ini adalah data pegawai, data gaji pegawai

\subsection{Metode Analisi}

Adapun alur penelitian untuk membangun sistem informasi penggajian pegawai ini menggunakan metode dengan model waterfall karena tahap demi tahap yang dilalui harus menunggu selesainya tahap sebelumnya dan berjalan berurutan. Model waterfall ini melakukan pendekatan sistematis dan urut mulai dari tahap kebutuhan sistem, tahap analisis, tahap perancangan (design), tahap implementasi (coding) dan tahap pengujian (testing dan maintenance).

\section{Hasil dan Pembahasan}

\section{PERANCANGAN}

\section{Form Login}

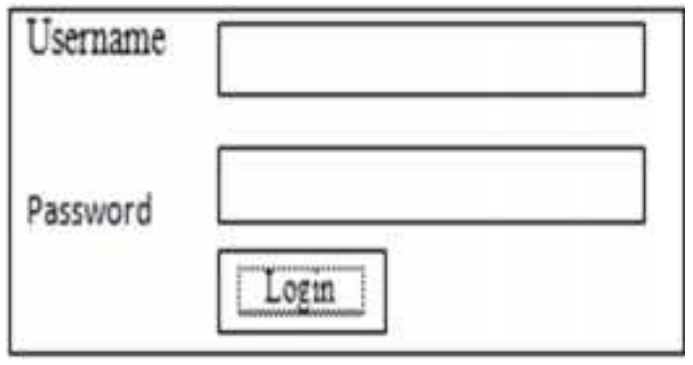

Gambar 2. form Login 


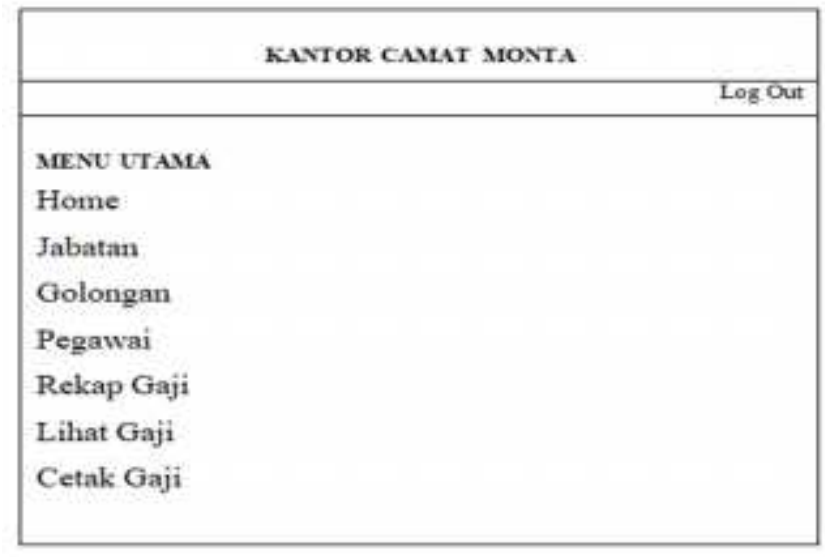

Gambar 3. Form Menu Utama

Form Data Jabatan

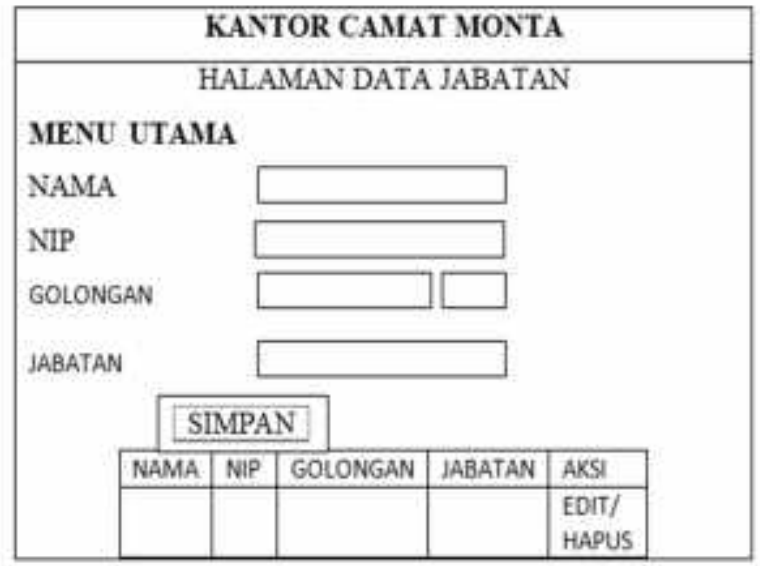

Gambar 4. Form Data Jabatan

Pengolahan Data Pegawai

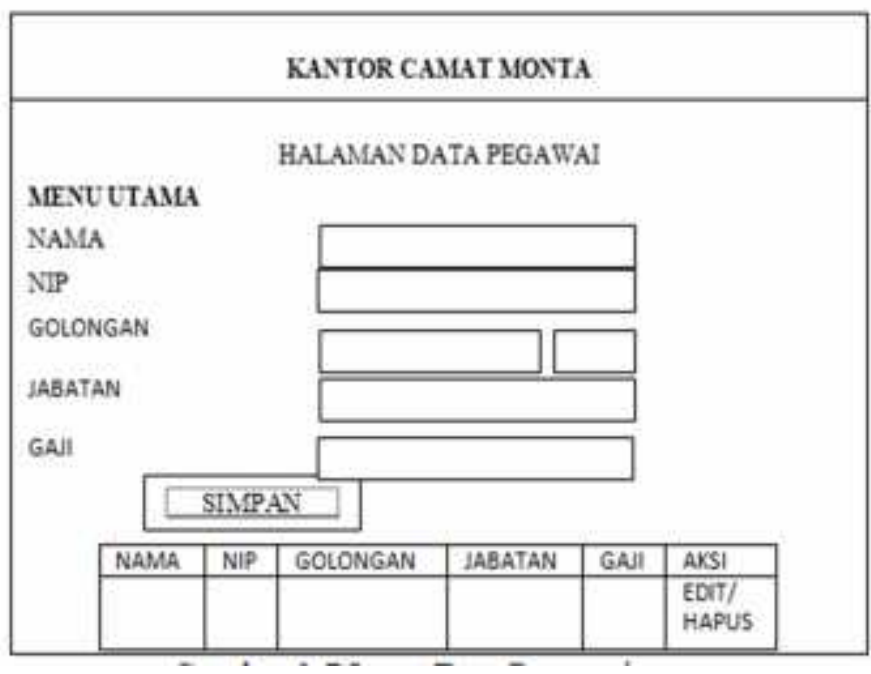

Gambar 5. Input Data Pegawai 
Pengolahan Data Golongan Pegawai

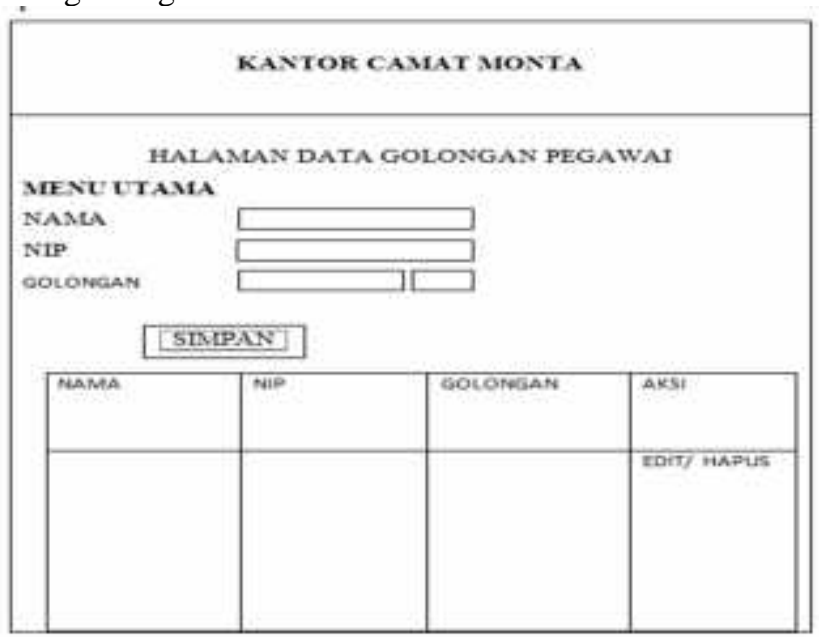

Gambar 6. Form Data Golongan Pegawai

\section{Pengolahan Rekap Golongan Pegawai}

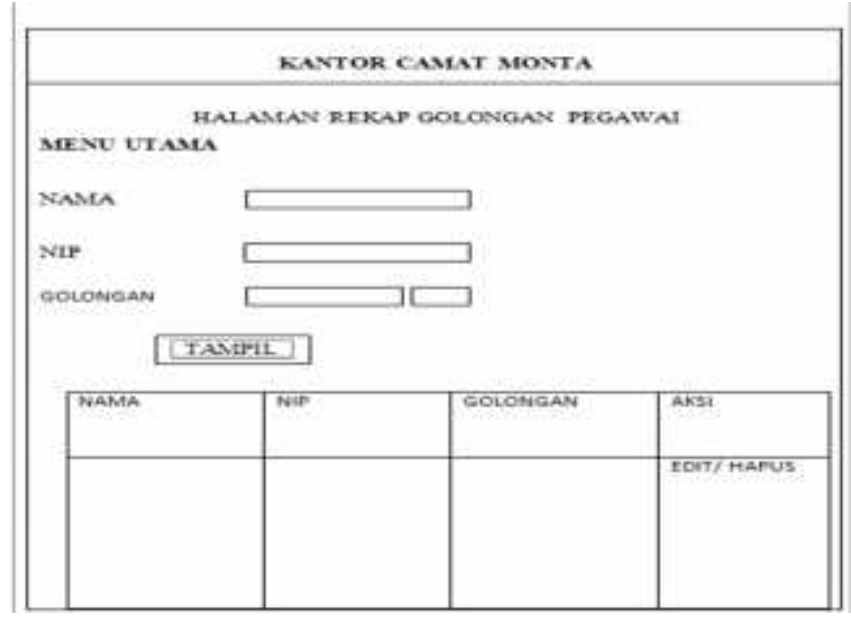

Gambar 7. Form Rekap Golongan Pegawai

\section{Pengolahan rekap gaji pegawai}

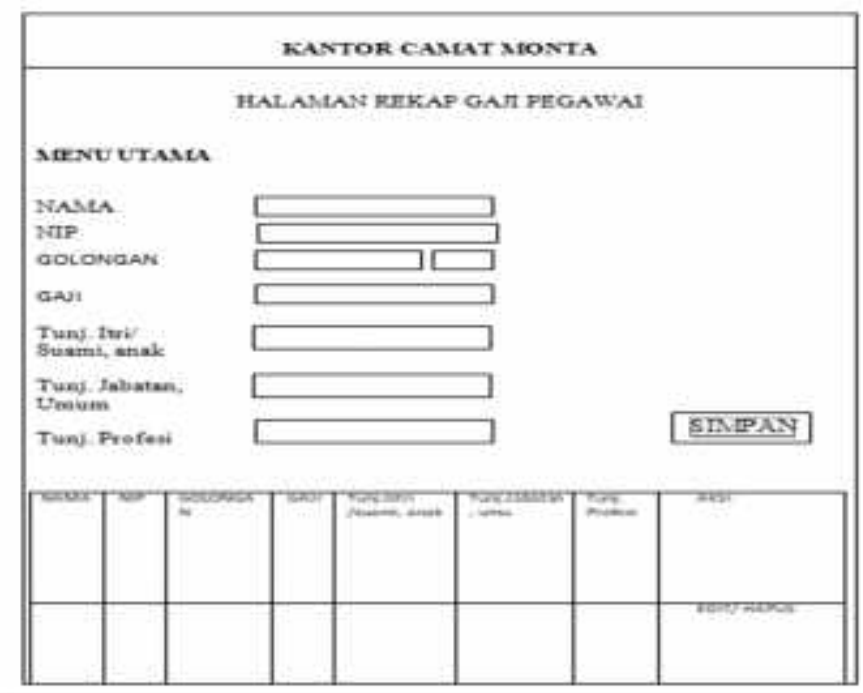

Gambar 8. Form Rekap Gaji Pegawai 


\section{Pengolahan Cetak Gaji Pegawai}

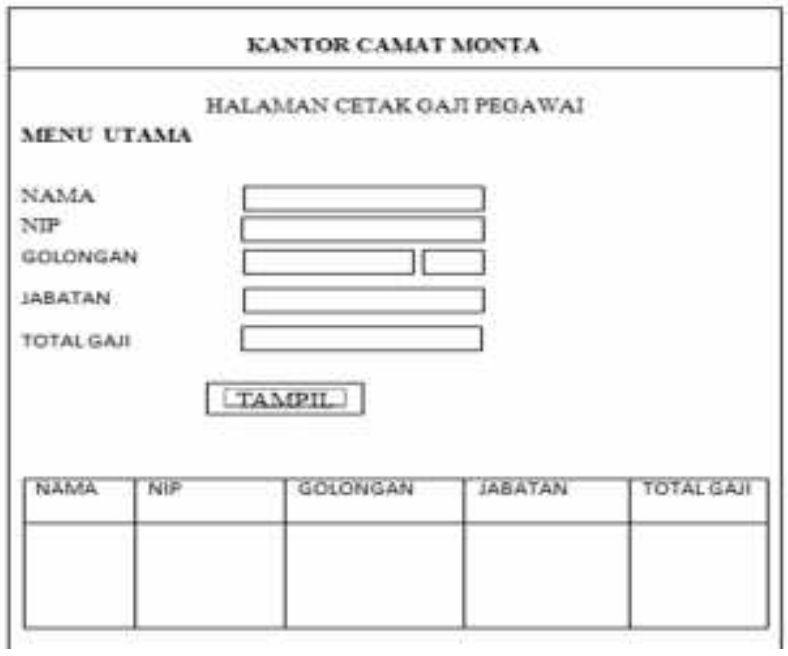

Gambar 9. Form Cetak Gaji Pegawai

Form Input Golongan

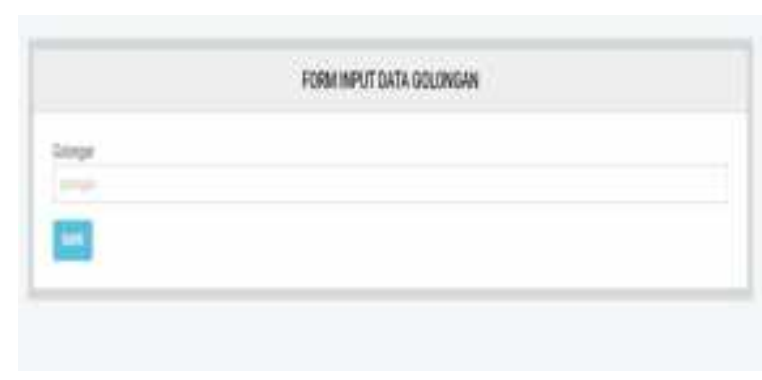

Gambar 10. Form Input Golongan

Dari gambar 10 terdapat Form input golongan merupakan perintah untuk menginput golongan kemudian di simpan.

Tampilan Golongan

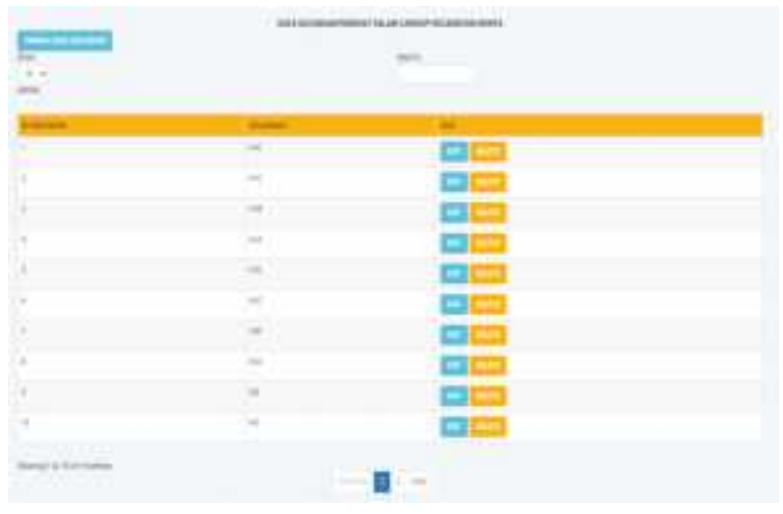

Gambar 11. Tampilan Golongan 
Dari gambar 11 terdapat untuk penambahan data, pencarian data, edit serta delete data yang sebelumnya di input.

\section{Form Input Gaji PNS}

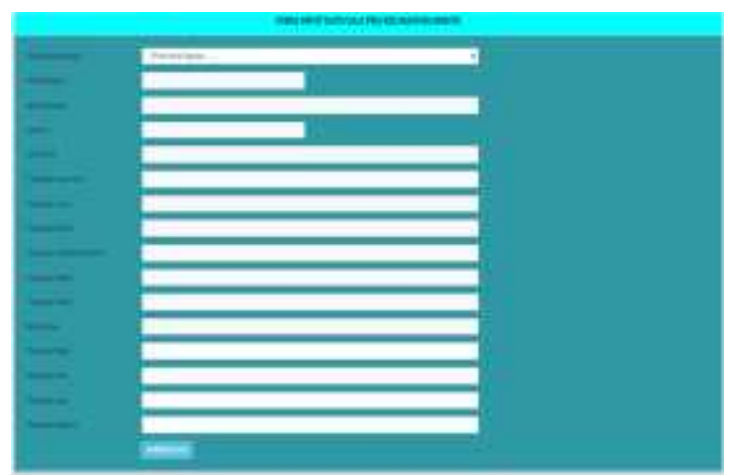

Gambar 12. Form Input Gaji PNS

Dari gambar 12 terdapat form yang berfungsi untuk menginput gaji dari PNS kemudian di simpan dan akan di lihat detail gaji pada tampilan gaji PNS

\section{Tampilan Data Gaji Pegawai PNS}

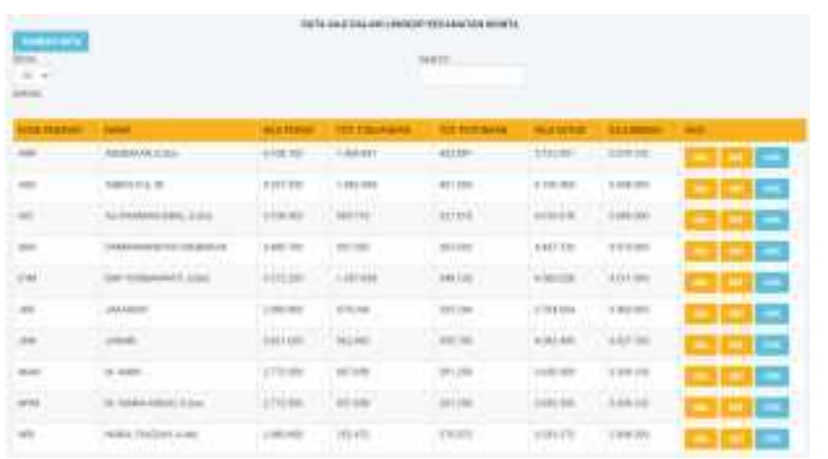

Gambar 13. Tampilan Data Gaji Pegawai PNS

Dari gambar 13 terdapat tampilan data gaji pegawai PNS hanya menampilkan nama pegawai, gaji pokok, total tunjangan, total potongan, gaji kotor, gaji bersih, dan bisa dilakukan pencetakan.

Form Input Gaji Pegawai Honorer

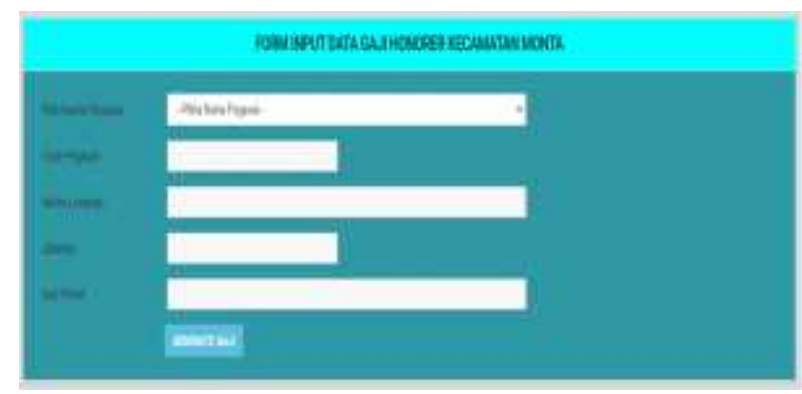

Gambar 14. Form Input Gaji Pegawai Honorer 
Dari gambar 14 terdapat Form untuk menampilkan gaji pegawai honorer yang sebelumnya telah di input kemudian di save. Sedangkan menurut (Aminudin et al., 2013) pada penelitiannya hanya menampilkan satu form untuk pegawai dan tidak menampilkan data penggajian pegawai yang berbeda berdasarkan jabatan.

\section{Tampilan Data Gaji Pegawai Honorer}

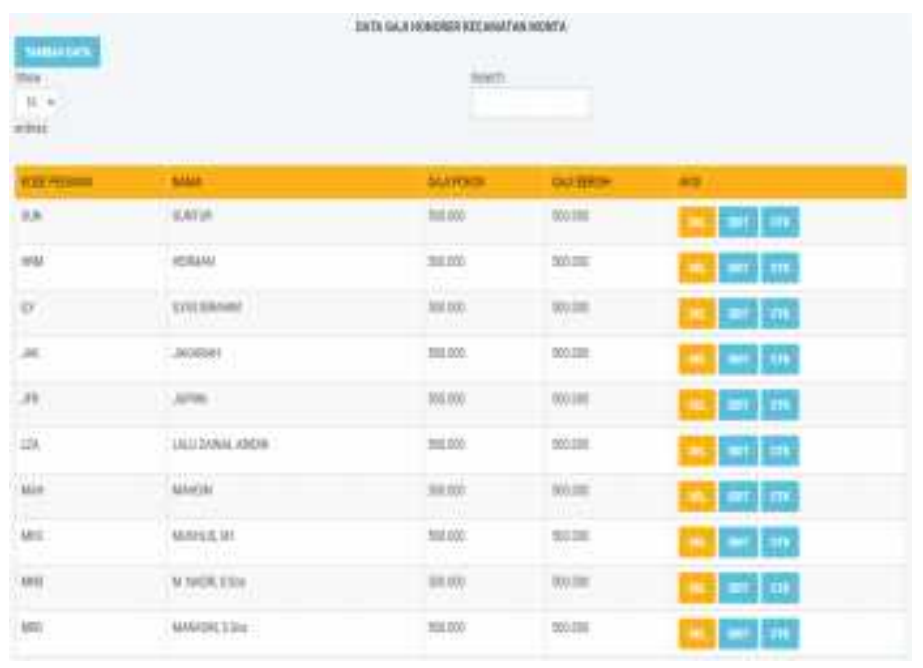

Gambar 29 Tampilan Data Gaji Pegawai Honorer

Dari gambar 29 terdapat tampilan data gaji pegawai honorer hanya menampilkan nama pegawai, gaji pokok, gaji bersih. Dan bisa melakukan penambahan dta, pencarian, pengeditan, dicetak, serta bisa dihapus.

\section{Kesimpulan}

5.

Berdasarkan hasil penelitian yang dilakukan, maka peneliti memberikan kesimpulan sebagai berikut

1. Sistem informasi manajemen penggajian pada kantor camat monta kabupaten bima berbasis web ini dirancang untuk dapat membantu dalam memudahkan pencarian informasi penggajian pegawai dengan pencarian informasi yang lebih cepat serta mengatasi kendala tentang ketidak-akuratan laporan-laporan yang berhubungan dengan masalah penggajian pegawai dapat diatasi secara online.

2. Implementasi sistem informasi manajemen penggajian pegawai pada Kantor Camat Monta Kabupaten Bima berbasis web ini diuji dengan menggunakan metode black box testing.

\section{Saran}

1. Semoga penelitian yang akan datang bisa mengambil subjek pada lokasi terdekat dari kampus agar mudah mengontrol

2. Bimbingan harus lebih proaktif sehingga bisa menyelesaikan penelitian tepat waktu. 


\section{Daftar Pustaka}

[1] Aminudin, A., Purnama, B. E., \& Wardati, I. U. (2013). Sistem Informasi Penggajian Pegawai Pada Kantor Kecamatan Nawangan Kabupaten Pacitan. Speed-Sentra Penelitian Engineering Dan Edukasi, 7(3).

[2] Haryadi, C., \& Arifin, R. W. (2016). Sistem Informasi Penggajian Karyawan Pada PT. White Horse Ceramic Indonesia. Bina Insani ICT Journal, 3(2), 370-383.

[3] Palevi, A. R., \& Krisnawati, K. (2014). Analisis Dan Perancangan Sistem Informasi Penerimaan Peserta Didik Baru Berbasis Website Pada SMP Negeri 2 Mojosongo Boyolali. Data Manajemen Dan Teknologi Informasi (DASI), 15(3), 1.

[4] Prasodjo, E. (2014). UNDANG-UNDANG APARATUR SIPIL NEGARA. Civil Service Journal, 8(1 Juni).

[5] Purnamasari, T. (2012). Pembangunan Sistem Informasi Pengolahan Data Pegawai Dan Penggajian Pada Unit Pelaksana Teknis Taman Kanak-Kanak Dan Sekolah Dasar Kecamatan Pringkuku. Speed-Sentra Penelitian Engineering Dan Edukasi, 5(2).

[6] Sari, L. K., \& Permadi, J. (2018). Aplikasi Penggajian Berbasis Web PT. Tirta Sukses Perkasa. Jurnal Sains Dan Informatika, 4(1), 13-19.

[ 7] Sidik, B. (2014). Pemrograman Web dengan PHP Revisi Kedua. Bandung: Informatika.

[ 8 ] Suharyanto, C. E., Chandra, J. E., \& Gunawan, F. E. (2017). Perancangan Sistem Informasi Penggajian Terintegrasi Berbasis Web (Studi Kasus di Rumah Sakit St. Elisabeth). Jurnal Nasional Teknologi Dan Sistem Informasi, 3(2), 225-232.

[ 9 ] Syifani, D., \& Dores, A. (2018). Aplikasi Sistem Rekam Medis Di Puskesmas Kelurahan Gunung. JUST IT: Jurnal Sistem Informasi, Teknologi Informasi Dan Komputer, 9(1), 22-31.

[ 10 ] Veza, M. O., \& Ropianto, M. (2017). Perancangan Sistem Informasi Inventory Data Barang Pada PT. Andalas Berlian Motors. Jurnal Teknik Ibnu Sina (JT-IBSI), 2(2), 121-134. 